\title{
Current Density Mapping and Optical Flow Visualisation of a Polymer Electrolyte Membrane Water Electrolyser
}

\author{
Ishanka Dedigama ${ }^{1}$, Pangiota Angeli ${ }^{1}$, Nicholas van Dijk ${ }^{2}$, Jason Millichamp ${ }^{1}$, \\ Dimitrios Tsaoulidis ${ }^{1}$, Paul R. Shearing ${ }^{1}$ and Daniel. J. L Brett ${ }^{1+}$ \\ ${ }^{1}$ Electrochemical Innovation Lab, Department of Chemical Engineering, UCL, \\ London, UK. \\ 2ITM Power, Sheffield, UK
}

\begin{abstract}
A polymer electrolyte membrane water electrolyser (PEMWE) employing a segmented current collector made from a printed circuit board (PCB) with optical access to the channel has been demonstrated for the first time. The cell allows the local current density, flow regime and bubble formation dynamics to be studied in real time. Transition from bubbly to slug flow is observed towards the end of the channel under higher bubble formation conditions which is associated with a significant increase in local current density.
\end{abstract}

\section{Keywords}

Current mapping; PEMWE; two-phase flow; flow visualisation; printed circuit board.

\footnotetext{
${ }^{\dagger}$ Corresponding author. Tel.: +44 (0)20 7679 3310; Fax: 44(0)20 73832348.

E-mail address: d.brett@ucl.ac.uk (D. J. L. Brett).
} 


\section{Introduction}

Proton exchange membrane water electrolysers (PEMWEs) are typically used to produce hydrogen from renewable energy sources (so called 'green hydrogen'), as they have a millisecond response time and are able to withstand intermittent electrical inputs without degradation. The technology is therefore promising as a component in future national power and transportation fuel systems. The PEMWE technology is cited in the European Hydrogen and Fuel Cell programme as a key process for transforming zero-carbon electricity sources into the supply of zerocarbon hydrogen and oxygen for miscellaneous end uses [1] and can act to accelerate the development of a hydrogen economy [2].

PEMWEs convert electrical energy to chemical energy by applying a DC voltage across an electrochemical cell. The anode and cathode are separated by a proton exchange membrane (typically Nafion) forming a zero gap electrolyser, gas diffusion layers (GDL) are used to supply current and aid diffusion, bipolar plates and end plates hold the cell / stack together. In such a system, water is introduced at the anode where it is oxidised to oxygen, with the production of hydrogen ions and electrons, as shown in Equation (1). Hydrated hydrogen ions $\left(\mathrm{H}^{+} \cdot x \mathrm{H}_{2} \mathrm{O}\right)$ migrate to the cathode through the membrane where they recombine electrochemically with electrons to produce hydrogen (Equation 2); the overall reaction corresponds to Equation (3) [3-6].

Anode: $\quad 2 \mathrm{H}_{2} \mathrm{O} \rightarrow \mathrm{O}_{2}+4 \mathrm{H}^{+}+4 e^{-}$ 
Cathode: $\quad 4 H^{+}+4 e^{-} \rightarrow 2 H_{2}$

Overall: $\quad \mathrm{H}_{2} \mathrm{O} \rightarrow \mathrm{H}_{2}+1 / 2 \mathrm{O}_{2}$

PEMWE technology has many advantages over other electrolysis methods such as alkaline and solid oxide electrolysis (SOEC) [7]. They are capable of achieving current densities over $2 \mathrm{~A} \mathrm{~cm}^{-2}$, reducing operational costs and potentially the overall cost of electrolysis. The thin polymer electrolyte membrane provides good proton conductivity, reducing Ohmic losses, and has a low gas crossover rate, yielding hydrogen with high purity [8]. Furthermore, PEMWEs are able to operate under high differential pressures (up to 350 bar) [9] and have a compact and simple design [10].

The first PEM electrolyser was developed by General Electric (USA) in 1966 for the purpose of oxygen generation [11, 12]. Currently, Giner, Inc. (USA) and Proton OnSite (USA) are the two major developers in the USA and report technologies capable of achieving system efficiencies close to $70 \%$ (LHV) $[13,14]$. However, the cost of hydrogen produced by commercially available PEMWE systems is currently estimated to be $\$ 4.8 / \mathrm{kg}-\mathrm{H}_{2}$ which exceeds the Department of Energy (DoE) targets [15]. ITM Power is the largest developer of PEMWEs in the UK and a major exponent of the UKH2Mobility program, which promotes hydrogen powered travel in the UK. ITM Power produce both small-scale self pressurising PEMWE systems (HPac 10 and HPac 40) as well as larger systems up to a megawatt (HFuel). The systems are able to produce hydrogen with $99.99 \%$ purity. The HFuel range are fully compliant and selfcontained for refuelling hydrogen powered vehicles or direct injection into the gas grid as a renewable energy storage system. . 
Despite promising commercial developments, the challenges of high cost (of which $\sim 70 \%$ is materials cost) and the need to improve efficiency persist. A large part of the materials cost of the electrolyser comes from the use of noble metals as electrocatalysts, as the acidity of the solid electrolyte precludes the use of non-noble metals. Typically, platinum [16], carbon supported platinum [17], carbon supported palladium [18] and carbon supported platinum / palladium [19] are used as the cathode electrocatalyst with the oxygen evolution reaction (OER) at the anode typically employing iridium, ruthenium (or their oxides) [18, 20-22], iridium / ruthenium oxide, iridium / tin oxide [23] or platinum / iridium electrocatalysts.

It is important to have a good understanding of the distribution of current in a PEMWE to optimise cell design, achieve maximum performance and longevity. To date, there are no studies present in the literature on experimental current density distribution (CDD) measurements of PEMWE systems. However, a number of methods for measuring local current density distribution in PEM fuel cells (PEMFC) have been reported.

Stumper et al. [24] presents different techniques for the determination of CDD in operating fuel cells: partial MEA approach, sub-cell approach [25] and the current distribution mapping technique that involves segmentation of the GDL and the use of a passive resistor network. Segmented flow field approach in PEM [26, 27] and solid oxide fuel cells (SOFC) [28], segmented membrane electrode assembly (MEA) approach [29] and specially designed segmented measuring gasket approach [30, 31] 
have also been investigated for CDD measurements. Two other major CDD measurement types [32] are the Hall effect sensor method [33] and the printed circuit board (PCB) approach [34-38].

PCB technology has been shown to be an effective way to make fuel cells $[39,40]$ and perform current mapping, as the approach has the advantages of fast prototype cycle times, low cost manufacture, high design flexibility and utilises low weight composite materials [41]. PCB technology was also implemented in our previous work on flow visualisation [42].

This study employs a segmented $\mathrm{PCB}$ and MEA approach to perform CDD measurements on a transparent single channel PEMWE such that two-phase flow features can be linked to current density distribution.

\section{Experimental}

\subsection{Synthesis of the catalyst coated membranes}

The Pt-Ru ink was prepared using a commercial Pt:Ru 50:50 atomic \% black powder from Alfa Aesar, UK. The ink was composed of aqueous dispersion of the catalyst, 40\% Nafion solution and $18 \mathrm{M} \Omega \mathrm{cm}$ deionised (DI) water (Millipore Milli- ${ }^{\circledR}$ system); the resulting ink was mixed in an ultra-sonic bath for $2 \mathrm{~h}$.

Two sheets of untreated Toray carbon paper, each with an area of $5.1 \mathrm{~cm}^{2}(0.6 \mathrm{~cm} \times$ $8.5 \mathrm{~cm}$ ), were cut and separated into 8 segments using $0.1 \mathrm{~cm}$ strips of Kapton ${ }^{\circledR} \operatorname{tape}$ 
The top and bottom segments have an area of $0.72 \mathrm{~cm}^{2}(0.6 \mathrm{~cm} \times 1.20 \mathrm{~cm})$ and the rest of the segments have an area of $0.54 \mathrm{~cm}^{2}(0.6 \mathrm{~cm} \times 0.9 \mathrm{~cm})$ each.

The brushing technique [8] was used to deposit the catalyst ink on the carbon paper followed by application of the decal method [43] to prepare the catalyst coated membranes (CCMs). The carbon sheets were painted with the catalyst ink after sonication and dried at $140{ }^{\circ} \mathrm{C}$ for $30 \mathrm{~min}$. The strips of Kapton ${ }^{\circledR}$ tape were peeled off and the coated carbon paper was weighed. The anode and cathode loadings were targeted to be $3.0 \mathrm{mg} \mathrm{cm}^{-2}$. The painted carbon sheets were then sandwiched on both sides of a $33 \mathrm{~cm}^{2}(3 \mathrm{~cm} \times 11 \mathrm{~cm})$ Nafion ${ }^{\circledR} 117$ membrane and hot-pressed at 500 psi pressure and $120^{\circ} \mathrm{C}$ for 4 min. The carbon papers on either side of the MEA composed were removed and weighed again to calculate the amount of catalyst transferred to the membrane. Finally, the CCM prepared was immersed in $18 \mathrm{M} \Omega \mathrm{cm}$ DI water to attain complete hydration. The membrane configuration and the dimensions of the segments are shown in Figure 1 (a).

\subsection{Design of the single channel PEMWE test cell}

The anode and cathode flow fields were machined from a $1.6 \mathrm{~cm}$ thick PCB using a CNC machine (Roland MDX 40). Each plate consisted of a single channel $(0.3 \mathrm{~cm} \times 8.5$ $\mathrm{cm})$ separated into 8 current collection segments. Shunt resistors with $2 \mathrm{~m} \Omega$ resistance were connected to each segment of the anode. The copper layers (35 $\mu \mathrm{m}$ thick) of both the anode and cathode boards were electroplated with a $0.25 \mu \mathrm{m}$ gold 
layer to avoid corrosion and to reduce contact resistance. The configuration of the segmented anode PCB plate is shown in Figure $1(b)$.

Figure 2(a) shows an exploded view of the electrolyser cell describing the components used and their assembly. A sheet of untreated (no Teflon content) Toray carbon paper (TGP_H_120) was used as the cathode GDL and the anode side was left unsupported (no GDL) in order to prevent lateral conduction of current between individual segments of electrode and to gain optical access to the electrode surface. The MEA and the cathode GDL were positioned between gasket material and flow field plates (that also acted as the current collectors) in such a way that one half of the MEA $(0.3 \mathrm{~cm} \times 8.5 \mathrm{~cm}$ strip) was in contact with the plates and the other half was aligned within the flow channel. The cell was held together using end plates made of $2 \mathrm{~mm}$ thick Perspex (with $3 \mathrm{~mm}$ wide channels) that had 12 bolts going through them which were tightened to a torque of $1.2 \mathrm{Nm}$, as shown in Figure 2 (b).

\subsection{Measurement system and procedure}

A schematic of the testing arrangement is shown in Figure 3. DI water $(18 \mathrm{M} \Omega \mathrm{cm})$ from the reservoir was pumped through the cell using a programmable peristaltic pump. The gasses produced were sent through dehumidification bottles and then to vent. The voltage across each of the shunt resistors on the anode flow-field plate was measures using an 18-bit data acquisition board (National Instruments, UK) to calculate the current generated from each segment. The main anode and cathode 
flow-field plates were connected to an Iviumsts.XRi high current potentiostat, A11700 (Alvatek Ltd, UK).

\subsection{CDD measurements}

The electrolyser cell was polarised to a range of operating voltages at different water flow rates $\left(1,3\right.$ and $\left.5 \mathrm{ml} \mathrm{min}^{-1}\right)$. The ratio of circulating water to the amount of water required to service the process, $(\zeta)$ has a value greater than $1(\zeta>1)$ throughout all voltage-current conditions when operated at these flow rates [42] to keep the membrane hydrated throughout the electrolysis process. The current densities for each current collector were inferred by measuring voltage drop across each of the shunt resistors.

\subsection{Optical visualisation measurements}

Images of the liquid and gas flow patterns along the channel and gas bubble formation were viewed using a high speed video system (Photron SA-5) with Solarc ${ }^{\circledR}$ light source for illumination. Images were obtained at a frame rate of $2000 \mathrm{fps}$ and at a resolution of $1024 \times 1024$. The images were digitally evaluated using Phantom Camera Control (PCC, version v2.14.727.0.) software. 


\section{Results}

\subsection{CDD along the electrolyser channel}

Figure 4 shows the CDD measurements across the 8 segments under 'low' (1.45 V), 'medium' (1.50 V) and 'high' (1.80 V) operating potentials at a water flow rate of 1 $\mathrm{ml} \min ^{-1}$. It can be seen that the current density distribution along the channel is relatively homogeneous at low operating potentials. However, while increasing the operating potential of the cell consistently leads to a local current increase at each segment, there is a significantly larger increase in current towards the end of the channel.

Figure 5 (a) and (b) show the current density variation across the 8 segments of the cell when operating at water flow rates of $3 \mathrm{ml} \mathrm{min}^{-1}$ and $5 \mathrm{ml} \mathrm{min}^{-1}$, respectively. The trend of CDD is similar to that observed in Figure 4.

These results demonstrate that the increase in water flow rate decreases the current density variation across the segments at low and medium operating potentials. Furthermore, it shows that at a fixed operating potential, the current densities across the segments decrease with increasing water flow rate, this can be explained by the decrease in cell temperature at higher water flow rates, as observed in our previous study [42] 


\subsection{Visual imaging of bubble size and two-phase flow patterns}

Studies have shown that the flow regime in an electrolyser can have a significant effect on performance [42]. Flow pattern visualisation and transition from bubbly to slug flow in an electrolyser has been studied in previous work by the authors [42]. However, there is little understanding of how the evolution of flow affects the local current distribution. By performing combined current density distribution and optical visualisation of bubble characteristics it is possible to reconcile the two.

Flow visualisation is capable of characterising the local flow regime: bubble flow is characterised by uniform distribution of discrete bubbles with diameter considerably smaller than the channel width $\left(D_{b}<w_{c h}\right)$ in a continuous liquid phase, whereas slug flow is characterised by 'bullet shaped' bubbles which have a diameter almost equal to the channel width $\left(D_{b} \approx w_{c h}\right)$ but with elongation along the channel direction.

Therefore, from first principles it can be determined that the criterion for bubbly flow is:

$\frac{D_{b}}{w_{c h}}<1$

and for slug flow:

$\frac{D_{b}}{w_{c h}} \cong 1$

The spherical bubbles in the bubbly region increase in volume as the flow transitions to the slug flow region, forming 'bullet shaped' bubbles with a length $l_{b}$, giving: $\frac{D_{b}}{l_{b}}<1$ 
Images obtained by direct visualisation of the electrolyser anode flow channel are shown in Figure 6. It can be seen that the regularity of bubble occurrence and their size increased with increasing total cell current, indicating an increase in oxygen gas generation. It also shows that the bubbles towards the top part of the cell (Segments 6-8) are larger and more numerous (frequent) than in the bottom part of the cell, this is due to both an accumulation of bubbles formed lower down in the channel and a higher rate of oxygen generation towards the top of the channel.

Furthermore, the visualisation shows a decrease in bubble size with increasing water flow rate at a constant operating potential which can be explained by the natural decrease in void fraction with increasing liquid flow rate. To explore the effect of increasing operating potential and water flow rate on bubble size and shape, representative images of bubbles under the operating conditions considered were obtained at Segment 7 and analysed. It was observed that larger bubbles had a high tendency to coalesce with smaller bubbles. In these cases, the total volumes of the bubble clusters were calculated in order to find the equivalent diameter. Close-up images of the two generic types of bubbles seen in the flow channel are shown in Figure 7. The mean bubble diameter and length values obtained by averaging 10 samples are given in Table 1.

It can be seen that the ratio of bubble diameter to bubble length has a value of $\sim 1$ at low and medium potentials for all flow rates. The mean bubble diameter (at Segment 7) increases from Low to Medium operating potentials and approaches a critical value after which it deforms and starts growing vertically, indicating a 
transition from bubbly to slug flow. For Low and Medium conditions, increasing flow rate leads to a smaller average bubble diameter as would be expected due to the lower void fraction of gas bubbles caused by higher liquid water flow rate.

Previous studies have shown that transition from bubbly to slug flow and bigger bubbles (based on whole cell analysis) enhance mass transport (bubble removal and water access to the electrode) in an electrolyser and hence results in better performance $[42,44-47]$. Figure 6 shows that the gas void fraction in the flow channels increase with operating potential and decreasing water flow rate. Our previous study discusses the influence of the void fraction on the mass transport coefficient, which states the it has an inverse relationship $[47,48]$.

A rising bubble in an electrolyser channel displaces water, creating a transverse motion of water around it (Figure 8 (b)). Larger bubbles cause a greater displacement of water, which, at a certain bubble diameter, can act to sweep bubbles off of the electrode surface (Figure 8 (c)). Removal of bubbles that are growing on the surface leads to a greater electrode surface area available for reaction. Furthermore, as observed in Figure 9, Taylor bubbles (slug flow) have a tendency to coalesce with smaller bubbles and remove them from the electrode surface. Therefore, it follows that local transition from bubbly to slug flow can be attributed to the increase in mass transport that results in an increase in current density along the channel. 


\section{Conclusion}

The combination of localised current density mapping and flow visualisation in a PEMWE has been demonstrated for the first time. Increased current density towards the end of the channel is seen to be correlated with enhanced mass transport due to the transition from bubbly to slug flow. The results suggest that for a given electrolyser localised current density distribution and water feed flow rate, there will be a characteristic 'entrance length' along the channel associated with transition from bubble to slug flow and the realisation of superior localised performance.

\section{Acknowledgments}

The authors would like to acknowledge the EPSRC (EP/G060991/1; EP/1037024/1; EP/K014706/1) for funding DJLB, ITM Power for provision of technical input and the EPSRC Loan Pool for use of the high-speed camera. PS acknowledges funding form the Royal Academy of Engineering.

\section{References}

[1] A Vision for Our Future, European Commission, Brussels, 2003.

[2] S.A. Grigoriev, V.I. Porembsky, V.N. Fateev, International Journal of Hydrogen Energy, 31 (2006) 171-175.

[3] F. Barbir, Solar Energy, 78 (2005) 661-669.

[4] J.D. Holladay, J. Hu, D.L. King, Y. Wang, Catalysis Today, 139 (2009) 244-260.

[5] P. Lessing, Journal of Materials Science, 42 (2007) 3477-3487.

[6] P.W.T. Lu, S. Srinivasan, Journal of Applied Electrochemistry, 9 (1979) 269-283. 
[7] M.N. Manage, D. Hodgson, N. Milligan, S.J.R. Simons, D.J.L. Brett, International Journal of Hydrogen Energy, 36 (2011) 5782-5796.

[8] M. Carmo, D.L. Fritz, J. Mergel, D. Stolten, International Journal of Hydrogen Energy, 38 (2013) 4901-4934.

[9] K.E. Ayers, E.B. Anderson, C. Capuano, B. Carter, L. Dalton, G. Hanlon, J. Manco, M. Niedzwiecki, ECS Transactions, 33 (2010) 3-15.

[10] R. García-Valverde, N. Espinosa, A. Urbina, International Journal of Hydrogen Energy, 37 (2012) 1927-1938.

[11] R.J. Davenport, F.H. Schubert, D.J. Grigger, Journal of Power Sources, 36 (1991) 235-250.

[12] P. Millet, R. Ngameni, S.A. Grigoriev, V.N. Fateev, International Journal of Hydrogen Energy, 36 (2011) 4156-4163.

[13] M. Hamdan, T. Norman, in: DOE Hydrogen and Fuel Cells Program, 2012, pp. II-31 - II-34.

[14] K.E. Ayers, A. Roemer, in: DOE Hydrogen and Fuel Cells Program, 2012, pp. II-35 - II-38.

[15] in, 2011 (interim Update), pp. 3.1-14.

[16] H. Wendt, E.V. Spinacé, A. Oliveira Neto, M. Linardi, Química Nova, 28 (2005) 1066-1075.

[17] S. Shidong, Z. Huamin, L.I.U. Bo, Z. Ping, Z. Yining, Y.I. Baolian, Electrochemical and Solid-State Letters, 10 (2007) B122-B125.

[18] K. Naga Mahesh, J. Sarada Prasad, M. Venkateswer Rao, V. Himabindu, A. Yerramilli, P. Raghunathan Rao, International Journal of Hydrogen Energy, 34 (2009) 6085-6088.

[19] S.A. Grigoriev, P. Millet, V.N. Fateev, Journal of Power Sources, 177 (2008) 281-285.

[20] S. Siracusano, V. Baglio, A. Di Blasi, N. Briguglio, A. Stassi, R. Ornelas, E. Trifoni, V. Antonucci, A.S. Aricò, International Journal of Hydrogen Energy, 35 (2010) 5558-5568.

[21] E. Slavcheva, I. Radev, S. Bliznakov, G. Topalov, P. Andreev, E. Budevski, Electrochimica Acta, 52 (2007) 3889-3894.

[22] S. Song, H. Zhang, X. Ma, Z. Shao, R.T. Baker, B. Yi, International Journal of Hydrogen Energy, 33 (2008) 4955-4961.

[23] E. Mayousse, F. Maillard, F. Fouda-Onana, O. Sicardy, N. Guillet, International Journal of Hydrogen Energy, 36 (2011) 10474-10481.

[24] J. Stumper, S.A. Campbell, D.P. Wilkinson, M.C. Johnson, M. Davis, Electrochimica Acta, 43 (1998) 3773-3783.

[25] Z. Liu, Z. Mao, B. Wu, L. Wang, V.M. Schmidt, Journal of Power Sources, 141 (2005) 205-210.

[26] M.M. Mench, C.Y. Wang, M. Ishikawa, Journal of The Electrochemical Society, 150 (2003) A1052-A1059.

[27] S.-S. Hsieh, Y.-J. Huang, Journal of Power Sources, 183 (2008) 193-204.

[28] M.M. Mench, C.Y. Wang, Journal of The Electrochemical Society, 150 (2003) A79-A85.

[29] N. Rajalakshmi, M. Raja, K.S. Dhathathreyan, Journal of Power Sources, 112 (2002) 331-336.

[30] H. Sun, G. Zhang, L.-J. Guo, H. Liu, Journal of Power Sources, 158 (2006) 326332.

[31] H. Sun, G. Zhang, L. Guo, H. Liu, International Journal of Hydrogen Energy, 34 (2009) 5529-5536. 
[32] L.C. Pérez, L. Brandão, J.M. Sousa, A. Mendes, Renewable and Sustainable Energy Reviews, 15 (2011) 169-185.

[33] J.J. Hwnag, W.R. Chang, R.G. Peng, P.Y. Chen, A. Su, International Journal of Hydrogen Energy, 33 (2008) 5718-5727.

[34] D.J.L. Brett, S. Atkins, N.P. Brandon, V. Vesovic, N. Vasileiadis, A.R. Kucernak, Electrochemistry Communications, 3 (2001) 628-632.

[35] D.J.L. Brett, S. Atkins, N.P. Brandon, N. Vasileiadis, V. Vesovic, A.R. Kucernak, Journal of Power Sources, 172 (2007) 2-13.

[36] R. Lin, H. Sander, E. Gülzow, A. Friedrich, ECS Transactions, 26 (2010) 229236.

[37] S.J.C. Cleghorn, C.R. Derouin, M.S. Wilson, S. Gottesfeld, Journal of Applied Electrochemistry, 28 (1998) 663-672.

[38] H. Nishikawa, R. Kurihara, S. Sukemori, T. Sugawara, H. Kobayasi, S. Abe, T. Aoki, Y. Ogami, A. Matsunaga, Journal of Power Sources, 155 (2006) 213-218.

[39] R. O'Hayre, D. Braithwaite, W. Hermann, S.-J. Lee, T. Fabian, S.-W. Cha, Y. Saito, F.B. Prinz, Journal of Power Sources, 124 (2003) 459-472.

[40] F.A. Daniels, C. Attingre, A.R. Kucernak, D.J.L. Brett, Journal of Power Sources 249 (2014) 247-262.

[41] A. Schmitz, S. Wagner, R. Hahn, H. Uzun, C. Hebling, Journal of Power Sources, 127 (2004) 197-205.

[42] I. Dedigama, P. Angeli, K. Ayers, J. Robinson, D. Tsaoulidis, P.R. Shearing, D.J.L. Brett, International Journal of Hydrogen Energy, (Submitted).

[43] J. Xie, K.L. More, T.A. Zawodzinski, W.H. Smith, Journal of The Electrochemical Society, 151 (2004) A1841-A1846.

[44] H. Wang, H.D. Dewald, W.P. Jepson, Journal of The Electrochemical Society, 151 (2004) B114-B123.

[45] D. Zheng, D. Che, Y. Liu, Corrosion Science, 50 (2008) 3005-3020.

[46] K. Yan, D. Che, International Journal of Multiphase Flow, 37 (2011) 299-325.

[47] I. Dedigama, T. J Mason, J. Millichamp, K. Ayers, P. R. Shearing, D.J.L. Brett , International Journal of Hydrogen Energy, (Submitted).

[48] L. Sigrist, O. Dossenbach, N. Ibl, International Journal of Heat and Mass Transfer, 22 (1979) 1393-1399. 


\section{List of figures}

Figure 1. (a) Distended image of the CCM showing catalyst layer dimensions and (b) configuration of the segmented PCB board.

Figure 2. (a) An exploded view of the cell illustrating the cell components and their assembly. (b) Illustration of an assembled electrolyser cell used for current mapping measurements.

Figure 3. Illustration of testing arrangement.

Figure 4. Current density distribution along the flow channel for the 8 segments at Low, Medium and High operating potentials when operating at a water flow rate of 1 $\mathrm{ml} \min ^{-1}$.

Figure 5. Current density of the segments at Low, Medium and High cell potentials and when operating at a water flow rate of (a) $3 \mathrm{ml} \mathrm{min}^{-1}$ and (b) $5 \mathrm{ml} \mathrm{min}^{-1}$.

Figure 6. Two-phase flow profiles of the anode of the electrolyser cell when operating under Low, Medium and High potentials and water flow rates of $1 \mathrm{ml} \mathrm{min}^{-}$ $1,3 \mathrm{ml} \mathrm{min}-1$ and $5 \mathrm{ml} \mathrm{min}^{-1}$.

Figure 7. Close-up of two types of bubbles observed in the electrolyser flow channel showing: (a) diameter measurement of spherical-type bubble and (b) length of slugtype (Taylor) bubble.

Figure 8. (a) Cross section of the electrolyser channel; (b) flow dynamics of a rising bubble in a channel with lower void fraction; and (c) higher void fraction.

Figure 9. The sweeping effect of a Taylor bubble rising up the electrolyser channel. 


\section{List of Tables}

Table 1. Mean diameter and length of bubbles (and their ratios) observed at low medium and high operating potentials and water flow rates of $1 \mathrm{ml} \mathrm{min}^{-1}, 3 \mathrm{ml} \mathrm{min}{ }^{-1}$

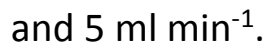

